\title{
Identifying Social Characteristics of Health-Related Information Seeker: A Gender-Specific Approach for Cancer Survivors
}

\author{
Minsoo Jung
}

\begin{abstract}
While health information-seeking behavior as an indicator of health communication of patients including cancer survivors has been researched, few studies have focused on how socioeconomic position and media use combine to influence health-related information seekers. This study examined social characteristics of health information-seeking behavior taking into account an individual's socioeconomic position and their media use in Korea, a developed country. The data for this study came from a survey of 1,010 respondents drawn from a nationally representative sample in the Republic of Korea. We conducted multivariate logistic regression analyses for gender-specific effects. We found that men who reported high household income were one and half times more likely to seek health information than those with low income status. We also found that women who performed Internet searches by computer at home were almost two times more likely to seek health information than those who did not. Similar results were found for men as well. Our analyses revealed that socioeconomic position and media use are associated with health information-seeking behavior by gender. Studies on information seekers may bring us more effective health promotion and relevant intervention for people with chronic conditions including cancer survivors.
\end{abstract}

Keywords: Cancer - health communication - mass media - socioeconomic factors - consumer health information

Asian Pac J Cancer Prev, 16 (5), 1865-1871

\section{Introduction}

Health information-seeking behavior (HISB) is active need-fulfillment behavior whereby health-related information is obtained from diverse sources, such as the mass media and Internet, and has emerged as an important issue within the transforming healthcare environment and the rise of medical consumers (Jung, Ramanadhan, and Viswanath, 2013; Jung, 2014a). However, little is known about the factors that affect HISB and its associations, and the social characteristics of HISB. Health information became highly universalized amid a wave of health news, pharmaceutical advertisements, medical industries, and health websites coupled with the recent emergence of usergenerated Internet content based on diverse healthcare information and communication platforms (Viswanath, 2005). Despite the abundance of health information, however, huge disparities exist between individuals in their levels of health knowledge, their interest in health information, and their information-searching behaviors (Viswanath, 2006; Jung, 2014a).

HISBs describe the actions of patients collecting the information necessary for their disease problem, as the patients try to address their stress or chronic condition such as cancer (Galarce, Ramanadhan, and Viswanath, 2011). Attention to information-seeking behaviors has increased as medicine shifted away from physician-driven models toward models of shared-decision-making in physician patient interactions (Rankin et al., 2000; Davison et al., 2002). Because informed survivors actively interact with their medical providers, they may be particularly able to accrue benefits in this shared system compared to survivors who are less informed (Charles et al., 2003; Kahn et al., 2007).

Health information-avoidance behaviors, meanwhile, are a plausible reaction when dealing with difficult situations (McCloud et al., 2013). Under threatening healthcare situations, people react by denying and avoiding the situations, rather than acting on them. For example, survivors may respond with inaction if they are overwhelmed by fear and despair (Leydon et al., 2000; Rees and Bath, 2001; Case et al., 2005). Information avoiders, unlike information seekers, often think that health information is too confusing to be useful or intentionally avoid it because of existing patient-physician relationships (Brashers, Goldsmith, and Hsieh, 2000; Czaja, Manfredi, and Price, 2003). The reasons for avoidance are varied, but they have the similar consequences of resulting in a lack of necessary health information, and potential health disparities among post-treatment patients (Ramanadhan and Viswanath, 2006).

Diverse health-related information can help strengthen 


\section{Minsoo Jung}

the individual's coping capacity (Arora et al., 2002; Huber and Cruz, 2000), boost self-efficacy (Lee et al., 2008), and encourage an active engagement in medical decisionmaking processes (Czaja et al., 2003). In fact, patient such as cancer survivors equipped with information experience fewer side effects and show better cognitive and social functioning (Schou et al., 2005). Additionally, many studies have found that HISBs are related to the people' preventive screening, reducing unhealthy behaviors, and enhancing treatment compliance (Rutten, Squiers, Hesse, and 2006; Czaja et al., 2003).

While HISBs as an indicator of health communication of patients has been studied, few studies have examined how social characteristics and socioeconomic position (SEP) combine to influence HISB (Jung, 2014a). The present study focused on the social determinants of HISB by examining the associations between health behavior, health status, and media use among the general population. By examining the relationship of media use and HISB, the present study sought to elucidate a gender-specific effect of HISBs among the population and to gain insights needed for formulating programs to mitigate health communication disparities between the information seeker and non-seeker groups. The following two research questions guided our analyses: (1) Which key social factors are associated with disparities in HISB? (2) Does media use mediate the associations between social determinants and HISB among the population?

\section{Materials and Methods}

\section{Study sample}

The data for this study came from a survey of 1,010 respondents drawn from a nationally representative sample of Korean adults who participated in Hankook Research's Master Sample PanelC. Members of this panel were recruited using a dual sampling frame, a combination of Random Digit Dial and Address-Based Sampling, which allows for sampling of individuals with no telephone land lines. The response rate for the survey was $57.0 \%$. Respondents received nominal cash incentives to participate in this survey. The surveys are administered online.

\section{Study design}

We investigated social characteristics of health-related information seekers in the developed country of South Korea. In particular, we examined determinants of healthinformation seeking behaviors in the relationship between individuals' socioeconomic position and their media use.

\section{Survey questions}

The questions in the survey were developed from previous surveys on health-information seeking behaviors (Viswanath, Ramanadhan, and Kontos, 2007; McCloud et al., 2013; Jung, 2014a; Jung, 2014b). We conducted five focus groups with participants from diverse sociodemographic backgrounds. In general, key themes gravitated around topics related to media use, preventive behavior, health communication, and general health status. This information was combined with items adapted from the Health Information National Trends Survey (HINTS). The survey was finalized after cognitive interviews with potential respondents.

\section{Measures}

Dependent variables: The main outcome variable was the health-related information seeking behaviors of the individuals. Respondents were asked to rate their own seeking activity on a five-point Likert type scale ranging from very actively to very inactively to the question “Thinking about all the times you've looked for healthrelated information from any source, how much do you search for information about health?" The answers were grouped into two categories. Respondents reporting "very inactively," "somewhat inactively," or "average" for information seeking status were coded as 0 and were considered as the information non-seeker group, while those reporting "very actively" or "somewhat actively" information seeking status were coded as 1 and were considered as the information seeker group.

Independent variables: SEP was measured by education and annual household income. For education, respondents were asked to identify their highest level of education completed: High School Degree or less; College Degree; Post Graduate Degree. For income, respondents were asked about their total annual household income before taxes: Under US\$20,000; \$20,000-39,999; $\$ 40,000-59,999 ; \$ 60,000-\$ 79,999 ; \$ 80,000$ or above. General media use was assessed with the following questions, "In the past seven days, how many hours do you watch television per day on average; listen to the radio; read a newspaper; search information by smartphone; and read news on the Internet by personal computer?". The response could range from 0 to 5 hours or more. Capacity to information was assessed in terms of utilization and access. We asked seven questions about barriers to finding desired health-related information. Participants were asked to note whether each issue was "a large problem, a small problem, or no problem at all in getting the information you wanted about [their] health." We conducted principal components analysis. The factors used to construct the information barrier index presented eigenvalues greater than 1 and factor loadings greater than 0.40. The first factor, named information access barriers, accounted for $32.4 \%$ of the total variance (Cronbach's alpha=0.73). This factor included four of the seven barriers: "access to the internet; difficulties using an on-line search tool or software; and the available information used too many technical terms." A second factor, named information utilization barriers, explained $26.4 \%$ of the total variance (Cronbach's alpha $=0.67)$. This factor included the remaining three potential barriers: "there was too much information; there was no way to tell if information was accurate; there was no way to tell if information was up-todate; there was no way to tell if information was relevant to my situation." These factors were recoded as reverse scale for accessing individual capacity to information. Regarding health status, respondents were asked to rate their own general health status on a five-point Likert type scale ranging from very good to very bad to the 
Identifying Social Characteristics of Health-Related Information Seekers: A Gender-Specific Approach for Cancer Survivors question "How is your health in general?" The answers were eventually grouped into two categories. Respondents reporting "very bad," "bad," or "average" for self-rated health (SRH) status were coded as 0 and were considered as the low-SRH group, while those reporting "very good" or "good" self-rated health status were coded as 1 and were considered as the high-SRH group. We also asked about instances of outpatient visits, including dental/oriental medicine treatment during the last month. The responses were grouped into two categories: yes or no.

Potential confounders: The potential confounders were age, gender, and region. In addition, the three dichotomous health behavior variables of smoking and drinking alcohol by gender were used in regression analyses. A value of 0 was assigned to "never smoke" for smoking and "did not drink during the past month" for drinking; all other responses were considered to be those of smokers and drinkers and were differentiated by assigning a value of 1 .

\section{Statistical analyses}

We identified differences in general characteristics between the information seeker and non-seeker groups using chi-square statistics. Multivariate logistic regression analyses analyzed the social determinants of health information-seeking gender-specific behavior among Koreans. All analyses were conducted by using STATA v.12.0 (STATA, College Station, TX).

\section{Ethics statement}

Approval for the study was granted by the Korea National Institute for Bioethics Policy Institutional Review Board (April 11, 2014; P01-201404-SB-19-00). All participants gave written informed consent to participate. The Ethics Committees of the Demographic Health Survey approved this consent procedure. During the data collection process, any information that could distinguish individual respondents was not collected.

\section{Results}

\section{General sample characteristics}

Of the 1,010 participants, $49.1 \%$ were women and $50.9 \%$ men (Table 1), $21.4 \%$ were in their $40 \mathrm{~s}$ and $18.7 \%$ were over 60 years of age or older. About $31.0 \%$ of the participants earned $\$ 20,000$ to $\$ 40,000$ per year. A majority of participants reported high SRH (84.2\%), most had a college degree or higher $(76.0 \%)$. Breast cancer was the most common cancer, having affected $47 \%$ of the participants (64\% of the females). Regarding medical utilization, $32.3 \%$ had received outpatient care during the last month. The descriptive characteristics of the sample from Table 1 indicated that the most frequently used media type was television and computer, to which $77.9 \%$ watched one hour more and $82.8 \%$ searched information using a computer, whereas, only $23.8 \%$ read newspapers

Table 1. General Characteristics of the Sample $(n=1,010)$

\begin{tabular}{|c|c|c|c|c|c|}
\hline Characteristic & $\mathrm{n}$ & $\%$ & Characteristic & $\mathrm{n}$ & $\%$ \\
\hline Gender & & & Television Watching & & \\
\hline men & 514 & 50.9 & $30 \mathrm{~min}$ or less & 100 & 9.9 \\
\hline women & 496 & 49.1 & $30 \mathrm{~min}$ to one hour & 123 & 12.2 \\
\hline Age & & & one to two hours & 299 & 29.6 \\
\hline $20-29$ & 204 & 20.2 & two to three hours & 261 & 25.8 \\
\hline $30-39$ & 202 & 20.0 & three hours or more & 227 & 22.5 \\
\hline $40-49$ & 216 & 21.4 & Radio Listening & & \\
\hline $50-59$ & 199 & 19.7 & no listening & 310 & 30.7 \\
\hline 60 or older & 189 & 18.7 & $10 \mathrm{~min}$ or less & 148 & 14.7 \\
\hline Education & & & $10 \mathrm{~min}$ to $30 \mathrm{~min}$ & 195 & 19.3 \\
\hline high school or less & 242 & 24.0 & $30 \mathrm{~min}$ to one hour & 169 & 16.7 \\
\hline college & 605 & 59.9 & one hour or more & 188 & 18.6 \\
\hline post-graduate & 163 & 16.1 & Newspaper Reading & & \\
\hline Income & & & no reading & 365 & 36.1 \\
\hline US $\$ 20 \mathrm{~K}$ or less & 174 & 17.2 & $10 \mathrm{~min}$ or less & 190 & 18.8 \\
\hline US\$20K-40K & 313 & 31.0 & $10 \mathrm{~min}$ to $30 \mathrm{~min}$ & 215 & 21.3 \\
\hline US\$40K-60K & 256 & 25.3 & $30 \mathrm{~min}$ or more & 240 & 23.8 \\
\hline US\$60K-80K & 159 & 15.7 & Smartphone Browsing & & \\
\hline US $\$ 80 \mathrm{~K}$ or more & 108 & 10.7 & no use or less than $10 \mathrm{~min}$ & 143 & 14.2 \\
\hline SRH & & & $10 \mathrm{~min}$ to $30 \mathrm{~min}$ & 207 & 20.5 \\
\hline high SRH & 850 & 84.2 & $30 \mathrm{~min}$ to one hour & 265 & 26.2 \\
\hline low SRH & 160 & 15.8 & one to two hours & 217 & 21.5 \\
\hline Chronic Disease & & & two hours or more & 178 & 17.6 \\
\hline have not & 697 & 69.0 & Computer Searching & & \\
\hline have & 313 & 31.0 & no use or less than $10 \mathrm{~min}$ & 45 & 4.5 \\
\hline Medical Utilization & & & $10 \mathrm{~min}$ to $30 \mathrm{~min}$ & 129 & 12.8 \\
\hline never & 365 & 36.1 & $30 \mathrm{~min}$ to one hour & 246 & 24.4 \\
\hline one time & 326 & 32.3 & one to two hours & 292 & 28.9 \\
\hline two times & 175 & 17.3 & two to three hours & 163 & 16.1 \\
\hline three times or more & 144 & 14.3 & three hours or more & 135 & 13.4 \\
\hline$\overline{\text { Total }}$ & 1,010 & 100.0 & & 1,010 & 100.0 \\
\hline
\end{tabular}


Table 2. Bivariate Analyses of the Sample by Health Information Seeking Behaviors

\begin{tabular}{|c|c|c|c|c|c|c|c|}
\hline Characteristic & $\begin{array}{l}\text { Non-Seeker } \\
(n=622)\end{array}$ & $\begin{array}{l}\text { Seeker } \\
(\mathrm{n}=388)\end{array}$ & $\mathrm{p}$-value & Characteristic & $\begin{array}{l}\text { Non-Seeker } \\
(n=622)\end{array}$ & $\begin{array}{c}\text { Seeker } \\
(\mathrm{n}=388)\end{array}$ & $\mathrm{p}$-value \\
\hline Gender & & & & Television Watching & & & \\
\hline men & 63.0 & 37.0 & ns & $30 \mathrm{~min}$ or less & 71.0 & 29.0 & $<0.1 \times<0.05$ \\
\hline women & 60.1 & 39.9 & & $30 \mathrm{~min}$ to one hour & 65.9 & 34.1 & \\
\hline Age & & & & one to two hours & 63.2 & 36.8 & \\
\hline $20-29$ & 69.1 & 30.9 & $<0.05$ & two to three hours & 56.7 & 43.3 & \\
\hline $30-39$ & 61.9 & 38.1 & & three hours or more & 58.6 & 41.4 & \\
\hline $40-49$ & 62.0 & 38.0 & & Radio Listening & & & \\
\hline $50-59$ & 62.3 & 37.7 & & no listening & 66.8 & 33.2 & $<0.01$ \\
\hline 60 or older & 51.9 & 48.1 & & $10 \mathrm{~min}$ or less & 64.2 & 35.8 & \\
\hline Education & & & & $10 \mathrm{~min}$ to $30 \mathrm{~min}$ & 64.6 & 35.4 & \\
\hline high school or less & 68.6 & 31.4 & $<0.05$ & $30 \mathrm{~min}$ to one hour & 58.0 & 42.0 & \\
\hline college & 59.5 & 40.5 & & one hour or more & 51.1 & 48.9 & \\
\hline post-graduate & 58.9 & 41.1 & & Newspaper Reading & & & \\
\hline Income & & & & no reading & 72.6 & 27.4 & $<0.001$ \\
\hline US $\$ 20 \mathrm{~K}$ or less & 70.1 & 29.9 & $<0.05$ & $10 \mathrm{~min}$ or less & 67.4 & 32.6 & \\
\hline US $\$ 20 \mathrm{~K}-40 \mathrm{~K}$ & 63.9 & 36.1 & & $10 \mathrm{~min}$ to $30 \mathrm{~min}$ & 57.7 & 42.3 & \\
\hline US\$40K-60K & 56.3 & 43.8 & & $30 \mathrm{~min}$ or more & 43.8 & 56.3 & \\
\hline US $\$ 60 \mathrm{~K}-80 \mathrm{~K}$ & 60.4 & 39.6 & & Smartphone Browsing & & & \\
\hline US $\$ 80 \mathrm{~K}$ or more & 55.6 & 44.4 & & no use or less than $10 \mathrm{~min}$ & n 65.7 & 34.3 & ns \\
\hline SRH & & & & $10 \mathrm{~min}$ to $30 \mathrm{~min}$ & 64.7 & 35.3 & \\
\hline high SRH & 62.0 & 38.0 & ns & $30 \mathrm{~min}$ to one hour & 61.9 & 38.1 & \\
\hline low SRH & 59.4 & 40.6 & & one to two hours & 59.4 & 40.6 & \\
\hline Chronic Disease & & & & two hours or more & 56.7 & 43.3 & \\
\hline have not & 66.6 & 33.4 & $<0.001$ & Computer Searching & & & \\
\hline have & 50.5 & 49.5 & & no use or less than $10 \mathrm{~min}$ & n 77.8 & 22.2 & $<0.1 \times<0.05$ \\
\hline Medical Utilization & & & & $10 \mathrm{~min}$ to $30 \mathrm{~min}$ & 66.7 & 33.3 & \\
\hline never & 75.9 & 24.1 & $<0.001$ & $30 \mathrm{~min}$ to one hour & 61.4 & 38.6 & \\
\hline one time & 57.7 & 42.3 & & one to two hours & 62.3 & 37.7 & \\
\hline two times & 50.3 & 49.7 & & two to three hours & 55.8 & 44.2 & \\
\hline three times or more & 47.9 & 52.1 & & three hours or more & 57.0 & 43.0 & \\
\hline
\end{tabular}

*n.s., Not significant

Table 3. Adjusted Odds Ratio and $95 \%$ Confidence Intervals for Reporting a health information seeker after Controlling for the Respondents' Characteristics

\begin{tabular}{|c|c|c|c|c|c|c|c|c|}
\hline & \multirow[t]{2}{*}{$\begin{array}{l}\text { Men } \\
\text { aOR }\end{array}$} & & & $\mathrm{p}$-value & \multirow[t]{2}{*}{$\begin{array}{c}\text { Women } \\
\text { aOR }\end{array}$} & \multicolumn{2}{|c|}{$95 \% \mathrm{CI}$} & \multirow[t]{2}{*}{$\mathrm{p}$-value } \\
\hline & & Lower & Upper & & & Lower & Upper & \\
\hline \multicolumn{9}{|l|}{$\overline{\text { Socioeconomic Position }}$} \\
\hline Education & 1.025 & 0.560 & 1.878 & ns & 1.549 & 0.817 & 2.936 & ns \\
\hline Income & 1.411 & 1.055 & 1.886 & $<0.05$ & 1.044 & 0.745 & 1.463 & ns \\
\hline \multicolumn{9}{|l|}{ Health Status } \\
\hline SRH (Ref.=low) & 1.000 & & & & 1.000 & & & \\
\hline High & 0.646 & 0.284 & 1.467 & ns & 0.756 & 0.301 & 1.896 & ns \\
\hline Chronic Disease $($ Ref. $=$ none $)$ & 1.000 & & & & 1.000 & & & \\
\hline Patient with chronic conditions & 2.023 & 1.393 & 2.938 & $<0.001$ & 1.956 & 1.308 & 2.924 & $<0.001$ \\
\hline Medical Utilization & 1.318 & 0.919 & 1.891 & ns & 1.586 & 1.051 & 2.394 & $<0.05$ \\
\hline \multicolumn{9}{|l|}{ Health Behavior } \\
\hline Smoking $($ Ref. $=$ none $)$ & 1.000 & & & & 1.000 & & & \\
\hline Smoker & 0.626 & 0.308 & 1.271 & ns & 0.347 & 0.054 & 2.231 & ns \\
\hline Drinking (Ref.=none) & 1.000 & & & & 1.000 & & & \\
\hline One or more during the last week & 0.561 & 0.255 & 1.234 & ns & 1.930 & 0.827 & 4.507 & ns \\
\hline \multicolumn{9}{|l|}{ Information-Seeking Capacity } \\
\hline Utilization Capacity & 1.020 & 0.714 & 1.459 & ns & 0.854 & 0.564 & 1.293 & ns \\
\hline Access Capacity & 1.304 & 0.838 & 2.028 & ns & 1.060 & 0.679 & 1.654 & ns \\
\hline \multicolumn{9}{|l|}{ Media Use } \\
\hline Television & 1.186 & 0.858 & 1.638 & ns & 0.885 & 0.604 & 1.297 & ns \\
\hline Radio & 1.005 & 0.789 & 1.280 & ns & 1.187 & 0.895 & 1.574 & ns \\
\hline Newspaper & 1.422 & 1.050 & 1.927 & $<0.05$ & 1.347 & 0.933 & 1.945 & ns \\
\hline Smartphone & 1.370 & 1.009 & 1.859 & $<0.05$ & 0.976 & 0.684 & 1.392 & ns \\
\hline Computer & 0.847 & 0.631 & 1.136 & $\mathrm{~ns}$ & 1.960 & 1.340 & 2.866 & $<0.001$ \\
\hline Nagel Kerke R2 & & 0.241 & & & & 0.294 & & \\
\hline
\end{tabular}

*Dependent variable is health information seeking behaviors: the non-seeker (0) and the seeker (1); All models are additionally adjusted for age and residence 
Differences between the health-related information seeker and non-seeker

As shown in Table 2, compared to the information non-seeker group, the seeker group had more individuals who were old age $(\mathrm{p}<0.05)$, more individuals with higher educational attainment $(\mathrm{p}<0.05)$, more individuals with higher annual income $(\mathrm{p}<0.05)$, more individuals with chronic disease $(\mathrm{p}<0.001)$, and; more individuals who had received medical utilization $(\mathrm{p}<0.001)$. Regarding media use, the seeker group had more individuals who were exposed to newspaper $(\mathrm{p}<0.001)$ and radio $(\mathrm{p}<0.01)$.

Social characteristics of health-related information seeker

As shown in Table 3, after controlling for respondents' age and residence, men who reported high household income were 1.411 times more likely to seek healthrelated information than those with low income status (95\%CI, 1.055-1.886). Also, the male individual with chronic conditions was 2.023 times more likely to seek health information than the healthy male without chronic diseases (95\% CI, 1.393-2.938). Similar results were found for women as well in terms of health status. The female individual with chronic conditions was 1.956 times more likely to seek health information than the healthy female without chronic diseases (95\%CI, 1.308-2.924). At the same time, women who received medical utilization during the last month were 1.586 time more likely to seek health information than those without medical utilization (95\% CI, 1.051-2.394). Regarding informationseeking capacity, there were no significant disparities in information utilization and access by the seeker and nonseeker groups. However, media use was associated with health information-seeking behavior. After controlling for potential confounders, men who read newspaper was 1.422 times more likely to seek health information than those who did not used newspaper (95\% CI: 1.050-1.927). Also, men who did an Internet search by smartphone were 1.370 times more likely to seek health information than those who did not (95\%CI: 1.009-1.859). Meanwhile, women who did Internet search by computer at home were 1.960 times more likely to seek health information than those who did not (95\%CI: 1.340-2.866)

\section{Discussion}

Our analysis revealed that HISB among the population is strongly associated with social characteristics such as socioeconomic position, medical utilization, and media use, after controlling for potential confounders. This study represented one of the first explorations of health information-seeking behavior from a social determinants perspective using a gender-based approach. Within the study, participants who were richer, had chronic disease, received medical service, and used mass media (newspaper, smartphone, and/or Internet) were more likely to search health-related information. The HISB activity of the population was possibly connected with self-care management such as coping with health information deficiency. At the same time, media use appeared to mediate the impact of socioeconomic position and HISB.
These results indicate significant associations between key social and individual factors that may influence HISB, thus validating intersectional approach to examining information inequalities. This may also consistent with other work, which suggests that communication inequality is one of the explanations linking social determinants and health outcomes (Ramanadhan and Viswanath, 2006; Kontos, Bennett, and Viswanath, 2007; Jung, 2014b). Communication inequalities can be defined as gaps in the generation, manipulation, and distribution of information at the group level, and gaps in access to information and its benefits at the individual level (Viswanath, 2006; Jung, 2013).

The findings in the current study indicate that in addition to individual factors, social determinants such as income and education may influence how individuals access, interact with, and process healthrelated information. These associations have also been documented in studies on health communication among the vulnerable population (Viswanath et al, 2007; McCloud et al., 2013). Moreover, these pathways differ by gender, arguing for a more nuanced understanding of information avoidance behavior (McCloud et al., 2013). The finding that an individual who has difficulty using and understanding health information were more likely to report information avoidance is supported in previous research (Miles, Voorwinden, and Chapman, 2008). Health information avoiders may become overwhelmed by health risks that are perceived as threatening; this may be exacerbated by overly complex information (Viswanath, 2005) in which risks of negative outcomes are not easy to interpret.

Our observation is also consistent with the notion that individuals of any socioeconomic position can work to protect their own health if they can access the resources and information required to do so (Randolph and Viswanath, 2004). The importance of mass media in health promotion and disease prevention is well documented, since both routine exposure to and strategic use of mass media play a significant role in changing health behaviors including HISB (Jung, Arya, and Viswanath, 2013; Jung, Chan, and Viswanath, 2014). Although mass media channels such as radio, television, and newspapers are important sources of information about infectious and/or chronic diseases (Viswanath et al., 2007; Jung, Lin, and Viswanath, 2013), media-poor groups do not have easy access to these channels (Jung, Chan, and Viswanath, 2014). In fact, individuals of lower SEP tend to gain less benefit from information flows than their counterparts of higher SEP (Viswanath, 2006). Thus, we need to further reduce communication inequalities in order to improve the average level of health information and to promote preventive behaviors.

There are several limitations in this study. As part of a cross-sectional research, this study has examined the causal relationships among variables by existing theories. These causal relationships should be further generalized based on massive longitudinal data on diverse chronic diseases. Furthermore, our dependent variable, while representing a first step to understanding HISB, is unable to address some of the finer-tuned information about 
information seeking, including frequency and type of information search.

Empirical evidence revealed that social and individual characteristics are associated with HISBs by gender. Health information is gradually gaining attention due to unmet health needs and the rising expectations for better prognosis and health recovery through informed decision-making (Rimer et al., 2004). Nevertheless, little research has focused so far on the gap between the information-seeking and information non-seeking groups. Identifying information seekers may be an important step in creating a tailored approach to a patient's care and to understanding each particular patient's information needs. HISB, which makes structural differences depending on socio-contextual factors, may be also affected by communication inequalities. Different groups in social class receive different opportunities for learning more about health, and may consequently cause communication inequalities. Our findings suggest that social determinants and individual characteristics play a role in understanding which group search health information more actively. Studies on HISB may bring us more effective health promotion and relevant interventions for people with chronic conditions including cancer survivors. We thus need to capture a population's communication inequalities including HISB as both the cumulative impact and output of socio-contextual determinants.

\section{Acknowledgements}

This work was supported by the National Research Foundation of Korea Grant funded by the Korean Government (NRF-2014S1A5A8012122)

\section{References}

Arora NK, Johnson P, Gustafson DH, McTavish F, Hawkins RP, Pingree $S$ (2002). Barriers to information access, perceived health competence, and psychosocial health outcomes: Test of a mediation model in a breast cancer sample. Patient Educ Couns, 47, 37-46.

Brashers DE, Goldsmith DJ, Hsieh E (2000). Information seeking and avoiding in health contexts. Health Commun Res, 28, 258-71.

Case DO, Andrews JE, Johnson D, Allard SL (2005). Avoiding versus seeking: The relationship of information seeking to avoidance, blunting, coping, dissonance, and related concepts. J Med Libr Assoc, 93, 353-62.

Charles CA, Whelan T, Gafni A, Willan A, Farrell S (2003). Shared treatment decision making: what does it mean to physicians? J Clin Oncol, 21, 932-6.

Czaja R, Manfredi C, Price J (2003). The determinants and consequences of information seeking among cancer patients. $J$ Health Commun, 8, 529-62.

Davison BJ, Gleave ME, Goldenberg SL, Degner LF, Hoffart D, Berkowitz J (2002). Assessing information and decision preferences of men with prostate cancer and their partners. Cancer Nurs, 25, 42-9.

Galarce EM, Ramanadhan S, Viswanath K (2011). Health information seeking. In: Thompson TL, Parrott R, Nussbaum JF (eds) The Routledge Handbook of Health Communication (pp. 167-180). New York, NY: Thompson Routledge.

Huber JT, Cruz JM (2000). Information needs and information- seeking behaviors of HIV positive men and women. Med Ref Serv $Q$, 19, 39-48.

Jung M (2013). Cancer control and the communication innovation in South Korea: Implications for cancer disparities. Asian Pac J Cancer Prev, 14, 3411-7.

Jung M, Arya M, Viswanath K (2013). Effect of media use on HIV/AIDS-related knowledge and condom use in SubSaharan Africa: A cross-sectional study. PLoS ONE, 8, 68359.

Jung M, Ramanadhan S, Viswanath K (2013). Effect of information seeking and avoidance behavior on self-rated health status among cancer survivors. Patient Educ Couns, 92, 100-6.

Jung M, Lin L, Viswanath K (2013). Associations between health communication behaviors, neighborhood social capital, vaccine knowledge, and parents' H1N1 vaccination of their children. Vaccine, 31, 4860-6.

Jung M (2014a). Determinants of health information-seeking behavior: Implications for post-treatment cancer patients. Asian Pac J Cancer Prev, 15, 6499-504.

Jung M (2014b). Associations of self-rated health and socioeconomic status with information seeking and avoiding behavior among post-treatment cancer patients. Asian Pac J Cancer Prev, 15, 2231-8.

Jung M, Chan CK, Viswanath K (2014). Moderating effects of media exposure on associations between socioeconomic position and cancer worry. Asian Pac J Cancer Prev, 15, 5845-51.

Kahn KL, Schneider EC, Malin JL, Adams JL, Epstein AM (2007). Patient centered experiences in breast cancer: Predicting long-term adherence to tamoxifen use. Med Care, 45, 431-9.

Kontos ZE, Bennett GG, Viswanath K (2007). Barriers and facilitators to home computer and internet use among urban novice computer users of low socioeconomic position. J Med Internet Res, 9, 31 .

Lee SY, Hwang H, Hawkins R, Pingree S (2008). Interplay of negative emotion and health self-efficacy on the use of health information and its outcomes. Commun Res, 35, 358-81.

Leydon ML, Boulton M, Moynihan C, Jones A, Mossman J, Boudioni M, et al (2000). Cancer patients' information needs and information seeking behavior: In depth interview study. $B M J$, 320, 909-913.

McCloud RF, Jung M, Gray SW, Viswanath K (2013). Class, race and ethnicity and information avoidance among cancer survivors. Br J Cancer, 108, 1949-56.

Miles A, Voorwinden S, Chapman S (2008). Psychologic predictors of cancer information avoidance among older adults: The role of cancer fear and fatalism. Cancer Epidemiol Biomarkers Prev, 17, 1872-1879.

Ramanadhan S, Viswanath K (2006). Health and the information nonseeker: A profile. Health Commun, 20, 131-9.

Randolph W, Viswanath K (2004). Lessons learned from public health mass media campaigns: Marketing health in a crowded media world. Ann Rev Public Health, 25, 419-37.

Rankin N, Newell S, Sanson-Fisher R, Girgis A (2000). Consumer participation in the development of psychosocial clinical practice guidelines: Opinions of women with breast cancer. Eur J Cancer Care, 9, 97-104.

Rees CE, Bath PA (2001). Information-seeking behaviors of women with breast cancer. Oncol Nurs Forum, 28, 899-907.

Rimer BK, Briss PA, Zeller PK, Chan EC, Woolf SH (2004). Informed decision making: What is its role in cancer screening? Oncol Nurs Forum, 28, 899-907.

Rutten LJF, Squiers L, Hesse B (2006). Cancer-related information seeking: Hints from the 2003 Health Information National Trends Survey (HINTS). J Health Commun, 11, 
Identifying Social Characteristics of Health-Related Information Seekers: A Gender-Specific Approach for Cancer Survivors 147-56.

Schou I, Ekeberg O, Sandvik L, Hjermstad MJ, Ruland CM (2005). Multiple predictors of health-related quality of life in early stage breast cancer: Data from a year follow-up study compared with the general population. Qual Life Res, 14, 1813-23.

Viswanath K (2005). The communications revolution and cancer control. Nature Rev Cancer, 5, 828-35.

Viswanath K (2006). Public communications and its role in reducing and eliminating health disparities. In: Thomson GE, Mitchell F, Williams MB (eds) Examining the health disparities research plan of the national institutes of health: Unfinished business (pp. 215-253). Washington, DC: Institute of Medicine.

Viswanath K, Ramanadhan S, Kontos EZ (2007). Mass media and population health: The macrosocial view (2007). In: Galea S (ed) Macrosocial determinants of population health (pp. 275-294). New York, NY; Springer Science and Business Media Publishers. 